\title{
Simulations with a dynamic reaction-diffusion model of the polymer grating preparation by patterned ultraviolet illumination
}

Citation for published version (APA):

Leewis, C. M., Jong, de, A. M., IJzendoorn, van, L. J., \& Broer, D. J. (2004). Simulations with a dynamic reaction-diffusion model of the polymer grating preparation by patterned ultraviolet illumination. Journal of Applied Physics, 95(12), 8352-8356. https://doi.org/10.1063/1.1751237

DOI:

10.1063/1.1751237

Document status and date:

Published: 01/01/2004

Document Version:

Publisher's PDF, also known as Version of Record (includes final page, issue and volume numbers)

Please check the document version of this publication:

- A submitted manuscript is the version of the article upon submission and before peer-review. There can be important differences between the submitted version and the official published version of record. People interested in the research are advised to contact the author for the final version of the publication, or visit the $\mathrm{DOI}$ to the publisher's website.

- The final author version and the galley proof are versions of the publication after peer review.

- The final published version features the final layout of the paper including the volume, issue and page numbers.

Link to publication

\footnotetext{
General rights

- You may freely distribute the URL identifying the publication in the public portal. follow below link for the End User Agreement:

www.tue.nl/taverne

Take down policy

If you believe that this document breaches copyright please contact us at:

openaccess@tue.nl

providing details and we will investigate your claim.
}

Copyright and moral rights for the publications made accessible in the public portal are retained by the authors and/or other copyright owners and it is a condition of accessing publications that users recognise and abide by the legal requirements associated with these rights.

- Users may download and print one copy of any publication from the public portal for the purpose of private study or research.

- You may not further distribute the material or use it for any profit-making activity or commercial gain

If the publication is distributed under the terms of Article 25fa of the Dutch Copyright Act, indicated by the "Taverne" license above, please 


\title{
Simulations with a dynamic reaction-diffusion model of the polymer grating preparation by patterned ultraviolet illumination
}

\author{
Christian M. Leewis, ${ }^{\text {a) }}$ Arthur M. de Jong, and Leo J. van IJzendoorn \\ Department of Applied Physics, Accelerator Laboratory, Eindhoven University of Technology, \\ P.O. Box 513, $5600 \mathrm{MB}$ Eindhoven, The Netherlands \\ Dirk J. Broer \\ Eindhoven Polymer Laboratories, Eindhoven University of Technology, P.O. Box 513, 5600 MB Eindhoven \\ and Philips Research Laboratories, Prof. Holstlaan 4, 5656 AA Eindhoven, The Netherlands
}

(Received 2 February 2004; accepted 24 March 2004)

\begin{abstract}
Simulations of volume fraction profiles formed during the lithographic preparation of polymer gratings are made with a reaction/diffusion model, based on the Flory-Huggins theory. Monomer migration is driven by a gradient in the chemical potential rather than a gradient in the concentration. If the chemical potential is used as the driving force, monomer migration is not only driven by a difference in concentration, or volume fraction, but also by other entropic effects: the differences in monomer length and the degree of crosslinking of a polymer network. The monomer volume fractions are simulated as a function of position for different ultraviolet intensities and various grating pitches. Profound edges of the monomer volume fractions caused by the fact that the reaction rate is high compared to the diffusion rate are both measured and simulated. An excellent agreement with nuclear microprobe measurements on the polymer gratings is obtained. (C) 2004 American Institute of Physics. [DOI: 10.1063/1.1751237]
\end{abstract}

\section{INTRODUCTION}

Optical applications for polymers with a modulation in the refractive index or film thickness are found in data transport, storage, and displays. ${ }^{1-3}$ Patterned ultraviolet (UV) illumination is a technique that is used to prepare polymer structures having a modulation in monomer unit concentration from a homogeneous mixture of two monomers. Some regions are illuminated by UV light and polymerization is started, while other regions remain dark. Monomer migration, induced by difference in properties of the monomers, during this polymerization process results in lateral differences in the monomer concentration. If two monomers with an intrinsic difference in refractive index are used, these concentration modulations directly correspond to a modulation of the refractive index. In previous articles, ${ }^{4-6}$ nuclear microprobe measurements were performed on polymer gratings, prepared from two (meth)acrylate monomers. Each monomer contains a marker element, e.g., $\mathrm{Si}, \mathrm{Cl}, \mathrm{F}$, which can easily be detected with proton induced $\mathrm{x}$-ray emission (PIXE) and proton induced gamma-ray emission (PIGE). As shown in these articles, the monomer migration process depends not only on reactivity induced concentration gradients but also on differences in molecular size, crosslinking properties of the monomers, and monomer/monomer and monomer/polymer interaction parameters.

In this article, the dynamic reaction/diffusion model, ${ }^{6}$ based on the Flory-Huggins theory, ${ }^{7-9}$ is used to simulate some specific grating preparation processes, where profound edges of the monomer-unit concentration profiles are found when the reaction rate is fast compared to the diffusion rate.

a) Author to whom correspondence should be addressed; c.m.leewis@tue.nl
It was shown previously ${ }^{6}$ that for some combinations of a mono- and a di(meth)acrylate, the total thickness is not a constant due to polymer swelling and that the concentration of the less reactive and three times smaller monoacrylate is higher in the illuminated regions. In this article, it is shown that profound edges in the obtained areal density and monomer unit profiles can be correctly simulated when the reaction time is fast compared to the diffusion time.

\section{EXPERIMENT AND SIMULATION PARAMETERS}

Gratings were prepared from mixtures of two (meth)acrylate monomers by patterned UV illumination between a plain glass slide and one with a patterned photomask. The cells were filled with the monomer mixture containing 0.1 wt $\%$ of photoinitiator (Irgacure 651). The samples were then illuminated through the photomask by a UV-light source (Philips PL10W/10) and fixed afterwards by uniform illumination. A more detailed description of the preparation procedure can be found in Ref. 4.

With the $3 \mathrm{MeV}$ proton microprobe at Eindhoven University of Technology, the areal densities, i.e., the mass summed over the entire film thickness per unit area of the film, for $\mathrm{C}, \mathrm{O}, \mathrm{Cl}, \mathrm{Si}$, and $\mathrm{F}$ as a function of the lateral position in the sample were determined by a combination of Rutherford backscattering spectrometry, PIXE and PIGE. The $\mathrm{H}$ content was estimated from the $\mathrm{C} / \mathrm{H}$ and $\mathrm{O} / \mathrm{H}$ ratios of the monomers. An analysis method that combines these three techniques and takes ion beam induced material loss during the measurement into account was used. ${ }^{4}$ In this way, the areal densities and mass fractions of all elements present 
were determined quantitatively and were easily converted into the monomer areal densities and mass fractions.

The reaction/diffusion model described in Ref. 6 is used to simulate the reaction/diffusion process by a set of parameters: the reaction rate constants of the two monomers $R_{1}$ and $R_{2}$, the diffusion coefficients of the two monomers $D_{1}(0)$ and $D_{2}(0)$, a surface energy driven diffusion coefficient $D_{s}(0)$, the relative size of the monomers $\nu_{1}$ and $\nu_{2}$, and $K_{1}$ and $K_{2}$, which are coefficients of the free volume theory ${ }^{10,11}$ that determine how the diffusion coefficients decrease with monomer conversion. The monomer size ratio $\nu_{1} / \nu_{2}$, was estimated from atomic Van der Waals radii of the molecules. Crosslinking monomers are denoted by $f=1$, and noncrosslinking monomers by $f=0$, which is related to the amount of swelling of the illuminated regions. Additional constants are the surface tension $\gamma$, the temperature $T$, the grating pitch $\lambda$, the film thickness $h$, the Flory-Huggins segment size $\nu_{\text {segment }}$, the initial volume fraction of monomer 1 $\varphi_{1}(x, 0)$, the molecular masses $M_{1}$ and $M_{2}$, and the maximum illumination time $t_{\max }$. Numerical parameters are $\Delta t$, the step size in time, and $L$, the number of spatial regions per period. Of all these model parameters, $K_{1}$ is used as a fitting parameter and for simplicity, $K_{2}=0$. The other parameters are either known or were estimated or determined independently.

The diffusion coefficients and reaction rates were determined from other experiments. The diffusion coefficients at zero degree of polymerization $D_{1}(0)$ and $D_{2}(0)$ were determined from nuclear microprobe measurements where two monomers were made to diffuse into each other, ${ }^{12}$ and the reaction rates $R_{1}$ and $R_{2}$ were determined from differential scanning calorimetry (DSC) measurements. ${ }^{6}$ With these values, a simulation of the monomer migration process is then obtained.

In the model, the total illumination time is divided into steps $\Delta t$. During each step, an amount of each monomer is converted into polymer in the $1 / 2 L$ illuminated regions, as given by their reaction rates $R_{1}$ and $R_{2}$. Then, for all $L$ regions, the chemical potential of both monomers and the diffusion coefficients $D_{1}, D_{2}$, and $D_{s}$ are determined with the monomer and polymer fractions in each region. After that, the monomer migration of each monomer is determined using the gradient in its chemical potential and the diffusion coefficients. Then, the process is repeated from the beginning for a next step $\Delta t$ until the maximum illumination time $t_{\max }$ is reached. More details are found in the previous article. ${ }^{6}$

First, the measurements of the system consisting of a mono- and a diacrylate, i.e., 2-chloroethylacrylate $(\mathrm{Cl}$ monoacrylate) and hexafluorobisphenol-'A'-diacrylate (F diacrylate), is presented. This system shows profound edges of the monomer unit and total areal density profiles when prepared at a short UV light source distance that causes a fast reaction rate. In the model, the diffusion coefficients and $K_{1}$ were taken the same as in a previous reference. ${ }^{6}$ Second, in order to study the effect of the grating pitch on the balance between reaction and diffusion time, a system consisting of the $\mathrm{Cl}$ monoacrylate and 1,3-bis(3-methacryloxypropyl)1,1,3,3-tetramethyldisiloxane ( $\mathrm{Si}$ dimethacrylate) was considered. Measurements and simulations were done for a number of different grating pitches varying from $2 \times 500$ down to $2 \times 25 \mu \mathrm{m}$ for two different UV light source distances. For the simulations, the grating pitch was varied and two different sets of values of the reaction rate constants were used, corresponding to the two different UV light source distances. The diffusion coefficients and $K_{1}$, were kept the same for all simulations.

\section{RESULTS AND DISCUSSION}

\section{A. Monomer unit profiles}

First, the grating prepared from a mixture of the $\mathrm{Cl}$ monoacrylate and the $\mathrm{F}$ diacrylate is examined. This grating is presented to show that the model can simulate the thick edges observed in the measurement. The experimental areal density and mass fraction profiles are measured with the microprobe and are shown in Figs. 1(a) and 1(b).

In order to simulate the measured profiles, the overall reaction rate constant measured with DSC is used: $k_{\mathrm{ov}}^{\text {grat }}$ $=(0.024 \pm 0.005) \mathrm{s}^{-1}$. The rates $R_{1}$ and $R_{2}$ in Table I are derived assuming $R_{2}=2 R_{1}$ and the overall rate is approximated by the weighted average of the reaction rate constants $R_{1}$ and $R_{2}$ over the initial molar fractions of $0.88 \mathrm{Cl}$ monoacrylate and $0.12 \mathrm{~F}$ diacrylate. The same values for the crosslinking parameters $f_{1}$ and $f_{2}$, the diffusion coefficients $D_{1}(0), D_{2}(0)$, and $D_{s}(0)$, the size parameters $\nu_{1}$ and $\nu_{2}$, and the $K_{1}$ and $K_{2}$ values are used as in an earlier presented similar system ${ }^{6}$ with the same monomers. An approximate density of $1000 \mathrm{~kg} / \mathrm{m}^{3}$ is assumed to convert volume fraction directly into mass fractions. All parameters are shown in Table I.

A comparison between simulation and measurement is shown in Fig. 1 for both the areal densities and the monomer mass fractions. It is shown that both the $\mathrm{Cl}$ monoacrylate and the $\mathrm{F}$ diacrylate migrate towards the illuminated area and that the less reactive $\mathrm{Cl}$ monoacrylate has a higher mass fraction in the illuminated regions. The valley depths of the areal densities in the dark regions of the simulation agree with those of the measurement, as shown by Figs. 1(a) and 1(c). Because the UV light intensity in this system is much higher than in the system of the previous article, ${ }^{6}$ the monomer cannot reach the middle of the illuminated regions and thick edges are observed, which were absent in the previous system. ${ }^{6}$ The thick edges in the simulation are similar in size to the ones in the measurements. The measurement shown in Fig. 1(a) also suggests a maximum in the F diacrylate areal density in the far left and right of the dark regions. The simulations presented in Fig. 1(c) show a more distinct structure in the dark regions near the boundaries with the illuminated regions. This behavior is explained by the fact that the F diacrylate mass fraction is higher in the dark regions than in the illuminated regions, as shown by the measurement and simulation in Figs. 1(b) and 1(d) in combination with the variations in total areal density caused by swelling, indicated in Figs. 1(a) and 1(c). The $\mathrm{Cl}$ monoacrylate and $\mathrm{F}$ diacrylate mass fractions in the illuminated and dark regions and the height and width of the thick edges, as shown in Fig. 1(b), are predicted correctly. Note that details of the diffusion and 
a)

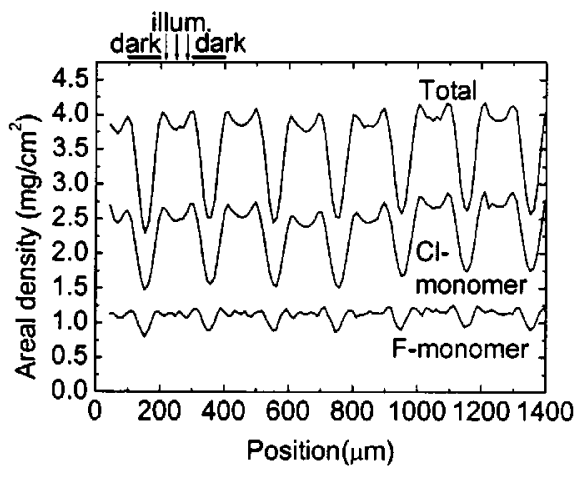

b)

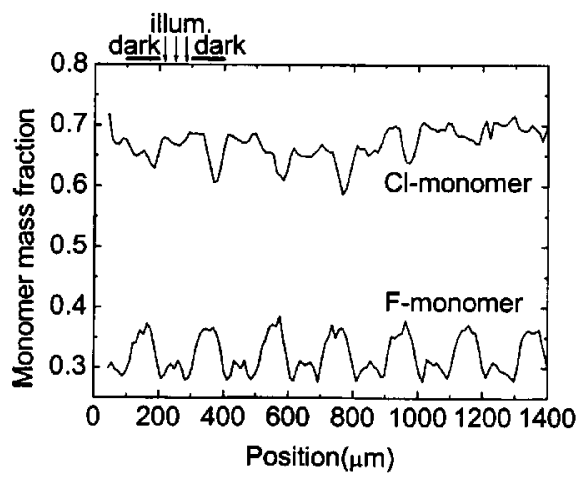

c)

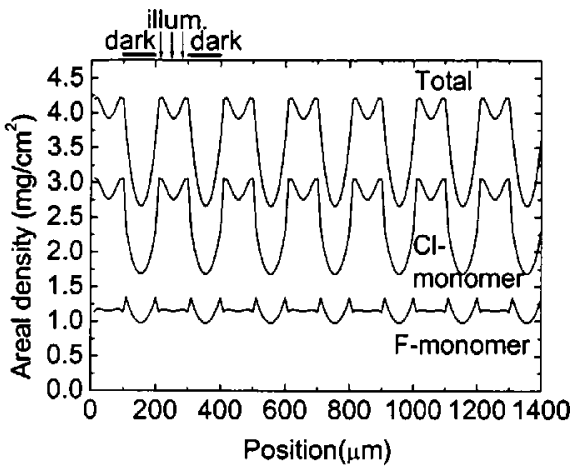

d)

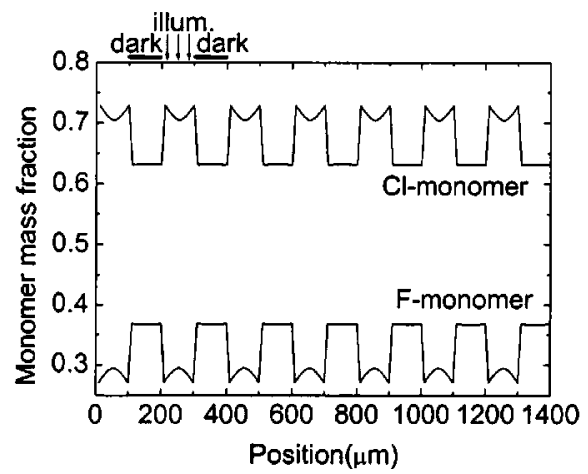

FIG. 1. Nuclear microprobe measurement (a) and simulation (c) of the total and the monomer areal densities of a mixture of the $\mathrm{Cl}$ monoacrylate and the F diacrylate, and measurement (b) and simulation (d) of the corresponding monomer mass fractions. reaction processes are only revealed by considering the mass fraction profiles.

\section{B. Variations in grating pitch}

Second, another set of simulations is made for a variation of the grating pitch for two UV light intensities. The first set was prepared at a UV light distance of $7.5 \mathrm{~cm}$ and the other one at $50 \mathrm{~cm}$, where the UV light intensity is 34 times lower and the reaction rate constant is about 5.9 times smaller. The overall rate constant for the mixing ratio considered here is estimated by $k_{\mathrm{ov}}^{\text {grat }}=(0.009 \pm 0.002) \mathrm{s}^{-1}$, for a UV light source distance of $7.5 \mathrm{~cm}$. This reaction rate constant corresponds to the one obtained by averaging the cho- sen reaction rate constants $R_{1}$ and $R_{2}$ over the molar fractions of $0.52 \mathrm{Cl}$ monoacrylate and $0.48 \mathrm{Si}$ dimethacrylate. The best results were achieved using $R_{2}=2.3 R_{1}$. This ratio determines the height of the edges and is reasonable since the Si dimethacrylate has two functional groups and methacrylates are in general more reactive than acrylates in copolymerization. ${ }^{13,14}$ For a light source distance of $7.5 \mathrm{~cm}$, the parameters are as shown in Table II, whereas for $50 \mathrm{~cm}$ the rate constants have to be divided by 5.9 and the total illumination time $t_{\max }$ is multiplied by the same value.

A comparison between measurements with the nuclear microprobe and the simulations is shown in Fig. 2. The measurements clearly show that for larger pitches, the monomer

TABLE I. The parameters used for the simulation of a combination of the $\mathrm{Cl}$ monoacrylate and the $\mathrm{F}$ diacrylate for a UV light source distance of $7.5 \mathrm{~cm}$.

\begin{tabular}{|c|c|c|c|}
\hline Reaction rate constants, etc. & $\begin{array}{l}R_{1}=2.12 \times 10^{-2} \mathrm{~s}^{-1} \\
R_{2}=4.67 \times 10^{-2} \mathrm{~s}^{-1}\end{array}$ & $\begin{array}{l}\nu_{1}=1 \\
\nu_{2}=3\end{array}$ & $\begin{array}{l}f_{1}=0 \\
f_{2}=1\end{array}$ \\
\hline Diffusion coefficients & $\begin{array}{l}D_{1}(0)=4.5 \times 10^{-10} \mathrm{~m}^{2} / \mathrm{s} \\
D_{2}(0)=1.5 \times 10^{-10} \mathrm{~m}^{2} / \mathrm{s} \\
D_{s}(0)=1.5 \times 10^{-6} \mathrm{~m}^{2} / \mathrm{s}\end{array}$ & $\begin{array}{l}K_{1}=0.21 \\
K_{2}=0 \\
\gamma=0.035 \mathrm{~J} / \mathrm{m}^{2}\end{array}$ & \\
\hline Initial values & $\begin{array}{l}\phi_{1}(x, 0)=0.68 \\
h(x, 0)=35.7 \mu \mathrm{m} \\
\lambda=200 \mu \mathrm{m}\end{array}$ & Parameters for numerical calculation & $\begin{array}{l}t_{\max }=80 \mathrm{~s} \\
\Delta t=6.25 \times 10^{-3} \mathrm{~s} \\
L=20\end{array}$ \\
\hline $\mathrm{Cl}$ monoacrylate & $\begin{array}{l}M_{1}=134.56 \\
\mathrm{Cl} \text { mass per unit } 35.453\end{array}$ & Other parameters & $\begin{array}{l}T=298 \mathrm{~K} \\
\nu_{\text {segment }}=134 \times 10^{-6} \mathrm{~m}^{3}\end{array}$ \\
\hline F diacrylate & $\begin{array}{l}M_{2}=444.33 \\
\text { F mass per unit } 6 \times 18.9984\end{array}$ & & \\
\hline
\end{tabular}


TABLE II. The parameters used for the simulation of a combination of the $\mathrm{Cl}$ monoacrylate and the Si dimethacrylate.

\begin{tabular}{|c|c|c|c|}
\hline Reaction rate constants, etc. & $\begin{array}{l}R_{1}=5.3 \times 10^{-3} \mathrm{~s}^{-1} \\
R_{2}=1.2 \times 10^{-2} \mathrm{~s}^{-1}\end{array}$ & $\begin{array}{l}\nu_{1}=1 \\
\nu_{2}=3\end{array}$ & $\begin{array}{l}f_{1}=0 \\
f_{2}=1\end{array}$ \\
\hline Diffusion coefficients & $\begin{array}{l}D_{1}(0)=4.5 \times 10^{-10} \mathrm{~m}^{2} / \mathrm{s} \\
D_{2}(0)=1.5 \times 10^{-10} \mathrm{~m}^{2} / \mathrm{s} \\
D_{s}(0)=3.0 \times 10^{-6} \mathrm{~m}^{2} / \mathrm{s}\end{array}$ & $\begin{array}{l}K_{1}=0.095 \\
K_{2}=0 \\
\gamma=0.035 \mathrm{~J} / \mathrm{m}^{2}\end{array}$ & \\
\hline Initial values & $\begin{array}{l}\varphi_{1}(x, 0)=0.27 \\
h(x, 0)=30.0 \mu \mathrm{m} \\
\lambda=\text { variable }\end{array}$ & Parameters for numerical calculation & $\begin{array}{l}t_{\max }=300 \mathrm{~s} \\
\Delta t=\text { variable } \\
L=\text { variable }\end{array}$ \\
\hline $\mathrm{Cl}$ monoacrylate & $\begin{array}{l}M_{1}=134.56 \\
\mathrm{Cl} \text { mass per unit } 35.453\end{array}$ & Other parameters & $\begin{array}{l}T=298 \mathrm{~K} \\
\nu_{\text {segment }}=134 \times 10^{-6} \mathrm{~m}^{3}\end{array}$ \\
\hline Si dimethacrylate & $\begin{array}{l}M_{2}=386.64 \\
\text { Si mass per unit } 2 \times 28.086\end{array}$ & & \\
\hline
\end{tabular}

diffuses less deep into the illuminated regions because it is converted into immobile polymer before it can reach the middle of these regions. For the $50 \mu \mathrm{m}$ pitch structures, it is most clearly observed that the thick edges are much more pronounced for the $7.5 \mathrm{~cm}$ UV light source distance than for the $50 \mathrm{~cm}$ distance for both the simulation and the measurement. In the latter case, the reaction is slower and the monomers have more time to diffuse towards the center of the illuminated region. For the $2 \times 100 \mu \mathrm{m}$ measurement in Fig. 2(a), the $\mathrm{Cl}$ signal in the illuminated regions is not high enough compared to the simulation. However, the mass frac-

a)

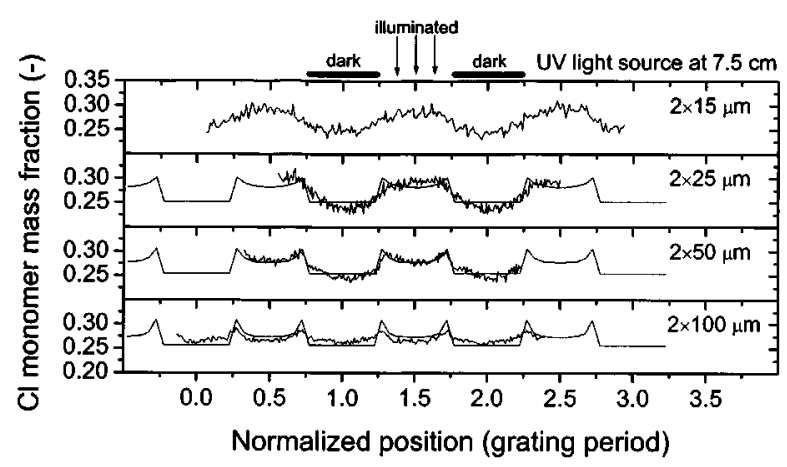

b)

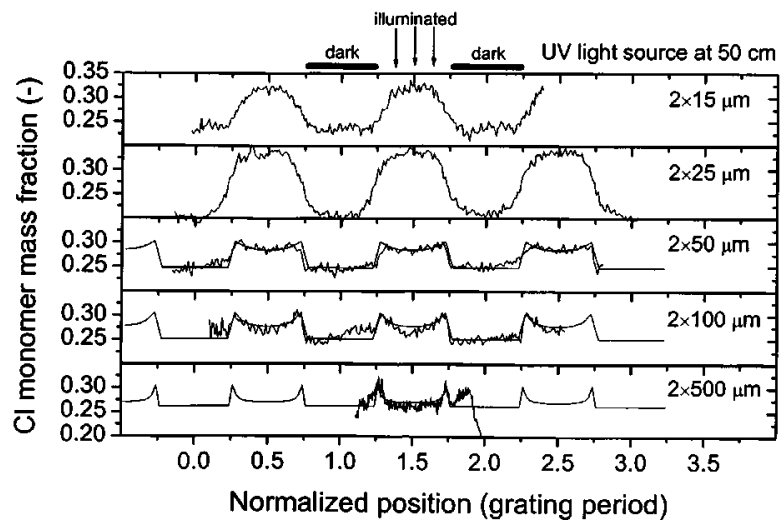

FIG. 2. Measurements and simulations of the $\mathrm{Cl}$ monoacrylate mass fraction of grating prepared from a mixture of the $\mathrm{Cl}$ monoacrylate and the $\mathrm{Si}$ dimethacrylate at a UV light source distance of $7.5 \mathrm{~cm}$ (a) and $50 \mathrm{~cm}$ (b). tion profiles in the illuminated regions can be simulated well with the measured diffusion coefficients ${ }^{12}$ when assuming a $K_{1}=0.095$.

The measurement of the $2 \times 25 \mu \mathrm{m}$ grating at $7.5 \mathrm{~cm}$ shows no thick edges while the simulation does. This is related to the fact that the UV light source is not a point source. Consequently, the transition between maximum and minimum light intensity becomes less sharp for smaller grating pitches. In particular, for the $2 \times 15 \mu \mathrm{m}$ pitch, the structure is poorly defined and no simulation is attempted.

For all cases of the $\mathrm{Si}-\mathrm{Cl}$ system, the simulations of the mass fractions were insensitive to the surface tension driven diffusion rate $D_{s}(0)$. When it is varied between $D_{s}(0)$ $=3.0 \times 10^{-6}$ and $1.2 \times 10^{-6} \mathrm{~m}^{2} / \mathrm{s}$, the difference in the mass fractions is less than $0.1 \%$.

For the $\mathrm{F}-\mathrm{Cl}$ system a value of $K_{1}=0.21$ was needed. For the $\mathrm{Si}-\mathrm{Cl}$ system, an even lower value was needed $\left(K_{1}=0.095\right)$, which corresponds to a steeper decrease of the diffusion coefficient with conversion than the $\mathrm{F}-\mathrm{Cl}$ and the $\mathrm{Si}-\mathrm{F}$ systems. ${ }^{6}$ This steep decrease cannot be explained by crosslinking alone.

In general, similar simulations are obtained for lower initial diffusion coefficients $D_{1}(0), D_{2}(0)$, and $D_{s}(0)$, if these are compensated for by a slower decrease of the diffusion coefficients with conversion, i.e., a higher value of $K_{1}$. For instance, assuming that $D_{1}(0), D_{2}(0)$, and $D_{s}(0)$ of Table I have an experimental error of a factor of 2, the corresponding error in $K_{1}$ is 0.08 . However, no suitable value of $K_{1}$ is found if the diffusion coefficients are changed by a factor of 10 or more.

\section{CONCLUSIONS}

A reaction/diffusion model based on the Flory-Huggins theory is used to describe the preparation process of polymer gratings by patterned UV photopolymerization of a mixture of two monomers. The reaction/diffusion mechanism is described using the chemical potential of the monomers in both the illuminated and the dark regions. The chemical potential incorporates the monomer volume fraction, which is determined by the reactivity, the monomer length, the crosslinking ability and the monomer/monomer and monomer/polymer 
interaction. For the current systems, it was not necessary to include interaction parameters. By inserting reaction rate constants obtained from DSC, estimations of the monomer length, and the experimentally measured diffusion coefficients into the dynamic reaction/diffusion model, simulations for a number of combinations of mono- and di(meth)acrylate monomers are obtained. These simulations correspond well with nuclear microprobe measurements. They correctly predict which monomer unit eventually has the highest volume fraction in the illuminated regions. In addition, they show that different reaction rates and grating pitches lead to different shapes of the monomer unit volume fraction and areal density profiles. When the reaction rate is high compared to the diffusion rate, the monomer cannot reach the center of the illuminated regions and the total areal density in the illuminated regions shows profound edges. The balance between the reaction rate and the diffusion coefficient is described correctly by the model.

The model contributes to the understanding of monomer diffusion processes during photopolymerization processes where the reaction rate constant depends on the position in the monomer mixture.

\section{ACKNOWLEDGMENTS}

Frank Watt and Ren Min Qin of the Research Center for Nuclear Microscopy of the National University of Singapore are acknowledged for their contribution to some of the Nuclear Microprobe measurements discussed here.

${ }^{1}$ H. J. Lee, M. H. Lee, M. C. Oh, J. H. Ahn, and S. G. Han, J. Polym. Sci., Part A: Polym. Chem. 37, 2355 (1999).

${ }^{2}$ M. Kagami, A. Kawasaki, and H. Ito, J. Lightwave Technol. 19, 1949 (2001).

${ }^{3}$ G. J. Steckman, R. Bittner, K. Meerholz, and D. Psaltis, Opt. Commun. 185, 13 (2000).

${ }^{4}$ C. M. Leewis, D. P. L. Simons, A. M. de Jong, D. J. Broer, and M. J. A. de Voigt, Nucl. Instrum. Methods Phys. Res. B 161-163, 651 (2000).

${ }^{5}$ C. M. Leewis, P. H. A. Mutsaers, A. M. de Jong, L. J. van IJzendoorn, D. J. Broer, and M. J. A. de Voigt, Nucl. Instrum. Methods Phys. Res. B 181, 367 (2001).

${ }^{6}$ C. M. Leewis, A. M. de Jong, L. J. van IJzendoorn, and D. J. Broer, J. Appl. Phys. 95, 4125 (2004).

${ }^{7}$ P. J. Flory, Principles of Polymer Chemistry (Cornell University Press, Ithaca, N.Y., 1953).

${ }^{8}$ R. A. L. Jones and R. W. Richards, Polymers at Surfaces and Interfaces (Cambridge University Press, Cambridge, MA, 1999).

${ }^{9}$ T. L. Hill, An Introduction to Statistical Thermodynamics (AddisonWesley, London, 1960)

${ }^{10}$ V. L. Colvin, R. G. Larson, A. L. Harris, and M. L. Schillings, J. Appl. Phys. 81, 5913 (1997).

${ }^{11}$ J. Xia and C. H. Wang, J. Polym. Sci., Part B: Polym. Phys. 33, 899 (1995)

${ }^{12}$ C. M. Leewis, P. H. A. Mutsaers, A. M. de Jong, L. J. van IJzendoorn, M. J. A. de Voigt, M. Q. Ren, F. Watt, and D. J. Broer, J. Chem. Phys. 120, 1820 (2004).

${ }^{13}$ Polymer Handbook, 3rd ed., edited by J. Brandrup and E. H. Immergut (Wiley, London, 1989).

${ }^{14}$ Copolymerization, edited by G. E. Ham (Wiley, New York, 1964). 